\title{
Heterogeneous Photocatalytic Degradation of Dyes in Water/Alcohol Solution Used by the Brazilian Agate Industry
}

\author{
Clóvia Marozzin Mistura ${ }^{1,2^{*}}$ (D) Ivo André Homrich Schneider ${ }^{2}$, Yasmin Vieira ${ }^{3}$ \\ ${ }^{1}$ Passo Fundo University, Passo Fundo, Brazil \\ ${ }^{2}$ Federal University of Rio Grande do Sul, Porto Alegre, Brazil \\ ${ }^{3}$ Federal University of Santa Maria, Santa Maria, Brazil \\ Email: ${ }^{\star}$ clovia@upf.br
}

How to cite this paper: Mistura, C.M., Schneider, I.A.H. and Vieira, Y. (2019) Heterogeneous Photocatalytic Degradation of Dyes in Water/Alcohol Solution Used by the Brazilian Agate Industry. Geomaterials, 9, 29-39.

https://doi.org/10.4236/gm.2019.91003

Received: November 29, 2018

Accepted: January 18, 2019

Published: January 21, 2019

Copyright $\odot 2019$ by author(s) and Scientific Research Publishing Inc. This work is licensed under the Creative Commons Attribution International License (CC BY 4.0)

http://creativecommons.org/licenses/by/4.0/

\begin{abstract}
The agate dyeing industry has been commonly seen as a high-pollution industry. Dyeing wastewater treatment is considered one of the most important categories for water-pollution control, because of its intense colour and the high concentration of organic contaminants. Most dyes used in the process present minimal biodegradability due to aromatic organic compounds in their structure. Using a photocatalytic reactor, experiments were carried out to study the decolorization of a water solution containing $8 \%$ ethylic alcohol and $200 \mathrm{mg} \mathrm{L}^{-1}$ of the dye Rhodamine $\mathrm{B}(\mathrm{RhB})$, the most difficult colorant to degrade among the used by the agate industry. The best conditions were further applied to treat the same agate water/ethyl alcohol solution containing a mixture of $200 \mathrm{mg} \mathrm{L}^{-1}$ of Rhodamine B (RhB), Crystal Violet (CV), Brilliant Green (BG), and Blood Red (BR). All the experiments were performed in a 2 $\mathrm{L}$ reactor equipped with ultraviolet (UV) lamps, at a wavelength of $365 \mathrm{~nm}$, with powdered $\mathrm{TiO}_{2}$ or $\mathrm{ZnO}$ as the catalyst. The results indicated that the optimal decolorization conditions were attained with $2.5 \mathrm{~g} \mathrm{~L}^{-1}$ of the catalyst at $\mathrm{pH} 10$ and an irradiation time of $80 \mathrm{~min}$. The process resulted in complete degradation of CV, BG and $80 \%-90 \%$ degradation of RhB and BR. The catalyst $\mathrm{ZnO}$ presented a performance somewhat better than $\mathrm{TiO}_{2}$. It is possible to conclude that the process of heterogeneous photocatalysis is effective for decolorization of water streams from the agate industry.
\end{abstract}

\section{Keywords}

Agate, Dye, Rhodamine B, Heterogeneous Photocatalysis, Advanced Oxidation Process 


\section{Introduction}

In the state of Rio Grande do Sul, located in the southern region of Brazil, there is a great occurrence of agate which is marketed worldwide [1]. Agate is a porous gemstone, commonly dyed to increase its value in the stone market [2]-[7]. Natural and artificially coloured agate plates are shown in Figure 1.

Agate geodes are treated and stained to produce handmade artefacts and jewelry that greatly increases their aggregate value. Unit operations involve storage, sorting, cutting, crushing, dyeing, polishing, washing, and finishing. Organic dyes used in this process present high colour intensity, minimal biodegradability and toxic effects. Wastewater generation is inevitable and, given the growing number of small-sized companies that process the stones, environmental discharge of such wastewaters is the cause for public concern [8]. Environmental legislation in the state of Rio Grande do Sul determines that, in order to dispose an effluent, it must comply with Resolution CONSEMA 355 of 2017 that states, among other parameters, that the effluent should not alter the natural colour of the receiving water body [9].

Conventional chemical treatment used by the agate industries to treat its effluents, such as sodium hypochlorite oxidation, despite of its low cost and ease of operation, performs poorly at it. Organic dyes are not completely oxidised by $\mathrm{NaClO}$ and many degraded compounds were found in the treated effluent, including organochlorides [10]. Other oxidation process is being suggested as an alternative to increase the treatment performance, such as ozonisation [11] and the Fenton's Reaction [12].

Like the Fenton's Reaction, heterogeneous photocatalytic decolorization is an advanced oxidation process (AOP) based in the generation of the hydroxyl radical $(\cdot \mathrm{OH})$, a chemical component with powerful oxidising potential. Heterogeneous photocatalysis is attractive since the process can be conducted using a low cost catalyst, such as $\mathrm{TiO}_{2}$ and $\mathrm{ZnO}$ along with $\mathrm{UV}$ radiation that could be furnished by a renewable energy source [13] [14] [15]. In this study, heterogeneous photocatalysis was tested to degrade the dyes present in a water/ethyl alcohol solution. Initially, the studies were conducted with Rhodamine B, considered the most difficult colorant to degrade among the used by the agate industry. The
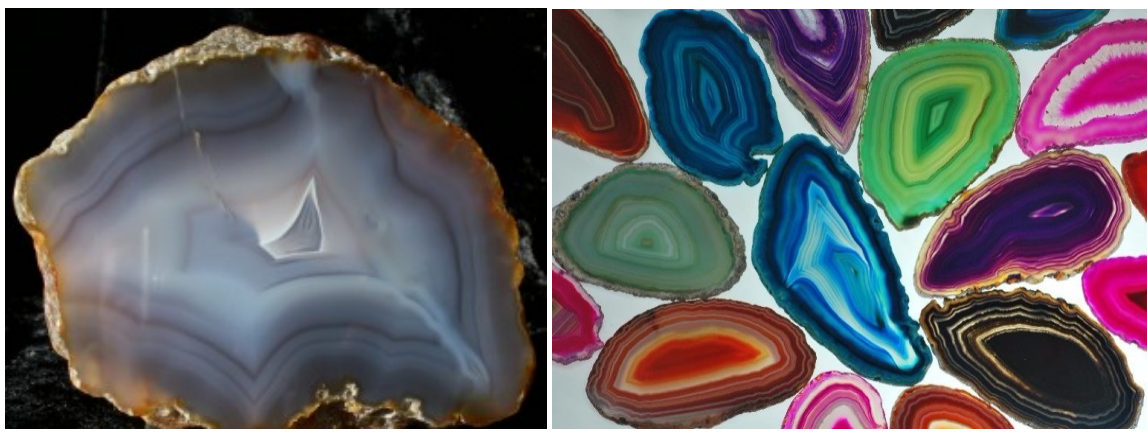

Figure 1. Raw agate and dyed agate plates in many colours. 
main operational variables studied were $\mathrm{pH}$, concentration of catalyst $\left(\mathrm{TiO}_{2}\right.$ and $\mathrm{ZnO}$ ) and UV irradiation time. Established the best condition, the treatment was applied to a water/alcohol solution containing a mixture of the colorants Rhodamine B, Crystal Violet, Brilliant Green and Blood Red combined.

\section{Materials and Methods}

\subsection{Reagents, Materials and Effluents}

The dyes were supplied by Merck ${ }^{\mathrm{Tm}}$ Brazil in order to provide the following colours: pink $=$ Rhodamine $\mathrm{B}(\mathrm{RhB})$; purple $=$ Crystal Violet $(\mathrm{CV})$; green $=$ Brilliant Green (BG); red (also called blood red, BR) by a composition of $30 \% \mathrm{w} / \mathrm{w}$ Basic Orange $2(\mathrm{BO})$ and $70 \%$ Rhodamine $\mathrm{B}(\mathrm{RhB})$. The general characteristics of each dye are presented in Figure 2.

$\mathrm{TiO}_{2}$ and $\mathrm{ZnO}$ powders were provided by $\mathrm{Synth}^{\mathrm{Tm}}$ and ethyl alcohol by $\mathrm{Nu}$ clear ${ }^{\mathrm{Tm}}$ Brazil. $\mathrm{NaOH}$ and $\mathrm{H}_{2} \mathrm{SO}_{4}$, used for $\mathrm{pH}$ adjustments, were provided by Sigma-Aldrich $\mathrm{Co}^{\mathrm{Tm}}$. Deionized water was purified using a Milli- $\mathrm{Q}^{\mathrm{TM}}$ water ion-exchange system $\left(1.8 \times 10^{7} \Omega \mathrm{cm}\right)$.

Synthetic effluent (SE) were prepared considering the following conditions: (a) aqueous solution containing $8 \%$ ethyl alcohol and $200 \mathrm{mg} \mathrm{L}^{-1}$ of $\mathrm{RhB}$; and (b) aqueous solution containing $8 \%$ ethyl alcohol and $200 \mathrm{mg} \mathrm{L}^{-1}$ of $\mathrm{RhB}, 200 \mathrm{mg} \mathrm{L}^{-1}$ $\mathrm{CV}, 200 \mathrm{mg} \mathrm{L}^{-1} \mathrm{BG}$, and $200 \mathrm{mg} \mathrm{L}^{-1} \mathrm{BR}$.

\subsection{Photooxidation Experiments}

All the experiments were performed in a $2 \mathrm{~L}$ capacity reactor equipped with UV lamps, at a wavelength of $365 \mathrm{~nm}$ [16]. UV radiation was provided by a $125 \mathrm{~W}$ HID/HPL (High Intensity Discharge/High Pressure Mercury Lamp, Philips ${ }^{\mathrm{Tm}}$ ) in the presence of powdered $\mathrm{TiO}_{2}$ or $\mathrm{ZnO}$ as the catalyst. The lamp's outer bulb was removed while the mercury and argon filled bulb was kept. In order to allow its

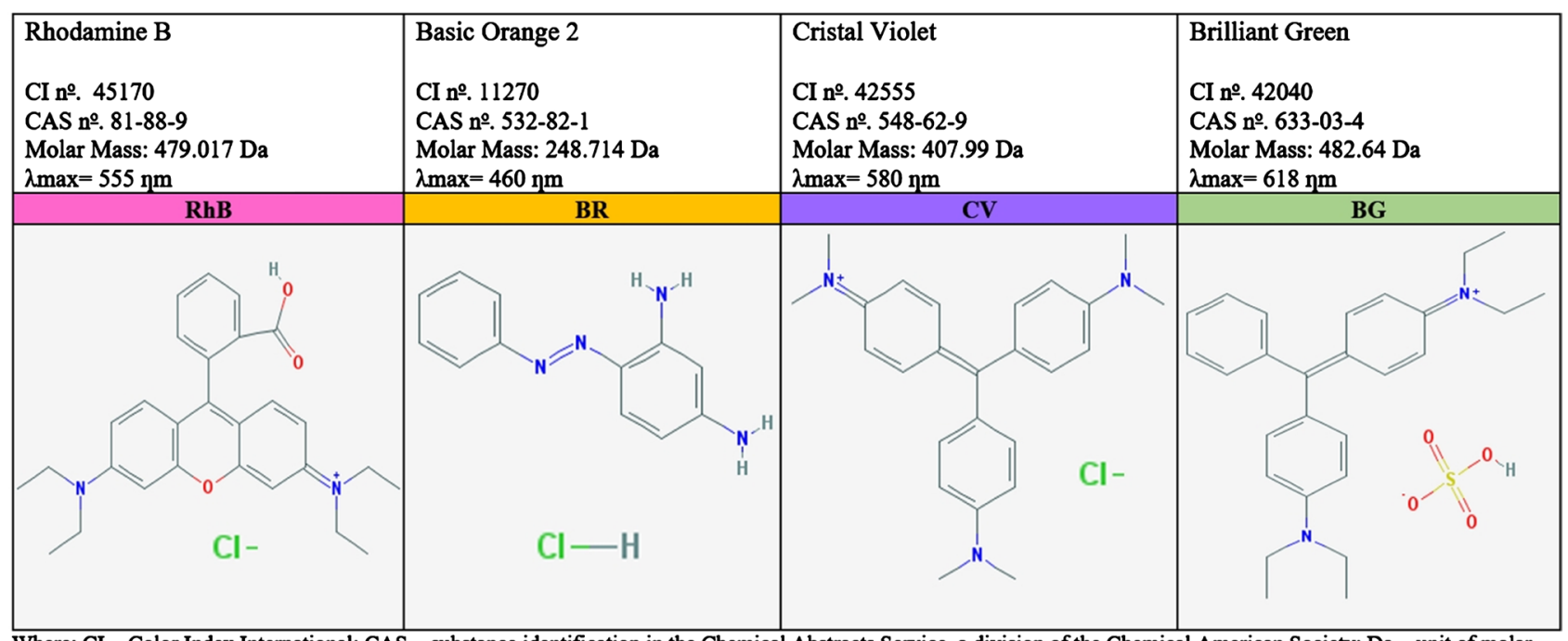

Where: $\mathbf{C I}=$ Color Index International; CAS = substance identification in the Chemical Abstracts Service, a division of the Chemical American Society; Da = unit of molar mass and $\lambda \max =$ wavelength of maximum absorption in $\eta \mathrm{m}$ (nanometer) adopted in this work.

Figure 2. Properties of the 4 dyes and representation of its chemical structures. 
immersion aiming total exposure of the samples to the radiation, the lamp was conditioned in a quartz tube (Figure 3 ).

The reaction time of the heterogeneous catalysis was 100 minutes, assisted by UV radiation the entire time. Samples were retrieved at 5 minutes intervals; the solid catalysts were withdrawn from the reactor by filtration using $\mathrm{TPP}^{\mathrm{rm}}$ polystyrene vacuum system with $0.22 \mu \mathrm{m}$ polyester sulfone membrane and the effluent was adequately diluted and evaluated in an UV-Vis spectrophotometer. The system was maintained at $30^{\circ} \mathrm{C}$ by means of a thermostatic bath and such temperature was kept throughout all the experiments. These procedures were applied to evaluate the effect of $\mathrm{pH}$ and catalyst concentrations. $\mathrm{pH}$ adjustment was carried out with solutions of sodium hydroxide and sulfuric acid. The concentration of $\mathrm{TiO}_{2}$ or $\mathrm{ZnO}$ applied were $0.0 \mathrm{~g} \mathrm{~L}^{-1}$ (control), $1 \mathrm{~g} \mathrm{~L}^{-1}, 2.5 \mathrm{~g} \mathrm{~L}^{-1}$ and 5.0 $\mathrm{g} \mathrm{L}^{-1}$.

The absorbance in the maximum wavelength $\left(\lambda_{\max }\right)$ was measured using a UV-Vis spectrophotometer (Shimadzu ${ }^{\mathrm{TM}} \mathrm{UV}$ 1800), each dye being determined at a specific maximum wavelength in the same analysis, $(\mathrm{RhB}=555 ; \mathrm{CV}=580 ; \mathrm{BG}$ $=618$ and $\mathrm{OB}=460 \mathrm{~nm}$ ). The absorption spectrum for the dye solutions ranging between 300 and $700 \mathrm{~nm}$ is shown in Figure 4. Calibration curves were performed in a concentration range of 0 to $20 \mathrm{mg} \mathrm{L}^{-1}$ for the dyes in an aqueous solution and its parameters are expressed in Figure 5.

\section{Results and Discussion}

The oxidation rates and efficiency of the photocatalytic system $\mathrm{UV} / \mathrm{TiO}_{2}$ and $\mathrm{UV} / \mathrm{ZnO}$ depend highly on the number operation parameters that govern the kinetics of the discoloration. Some of these parameters are temperature, $\mathrm{pH}$, concentration of the solid semiconductor, and light incidence time. These parameters either raise or reduce the reaction rate depending on the pollutant's structural complexity and hydrophobic tendencies [17]. It has been reported that minor incremental changes in temperature do not significantly affect the rate of

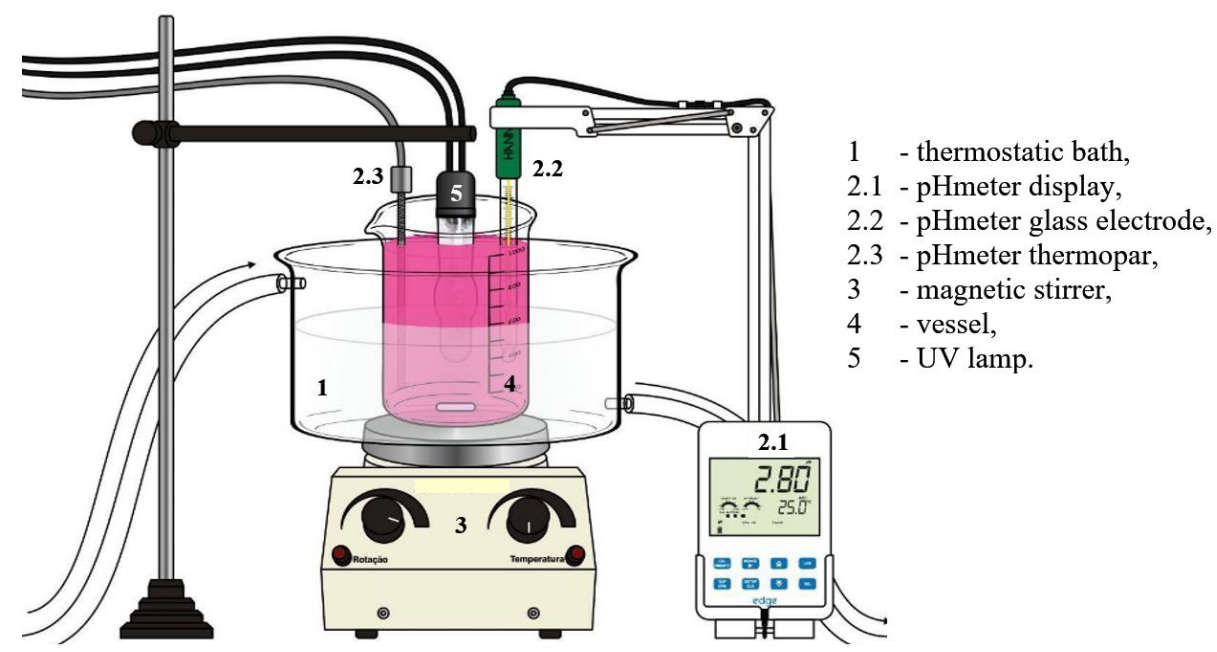

Figure 3. Schematics of a heterogeneous photocatalysis reactor. 


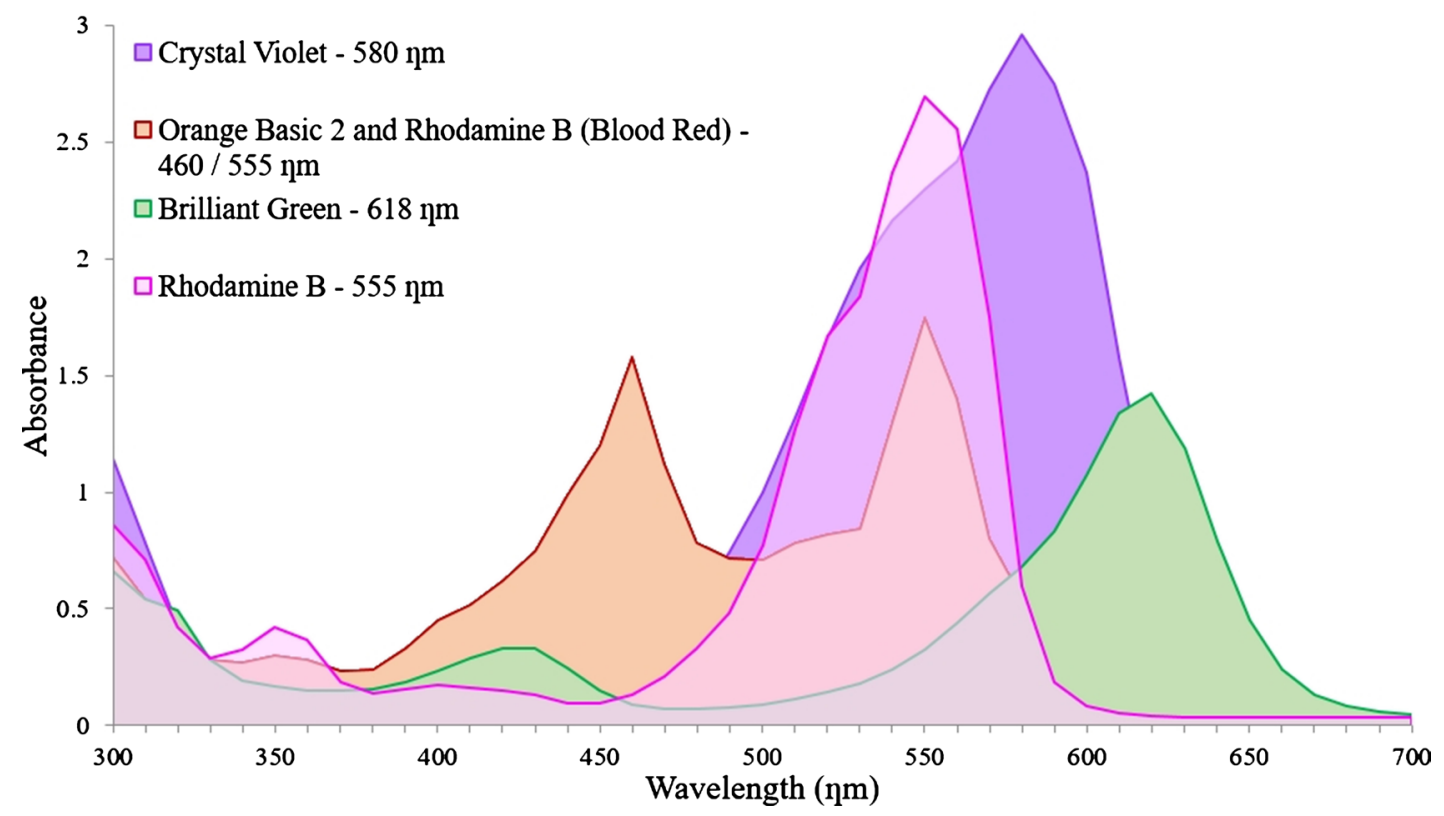

Figure 4. Visible absorption spectrum of the aqueous solution containing $20 \mathrm{mg} \mathrm{L}^{-1}$ for each dye.
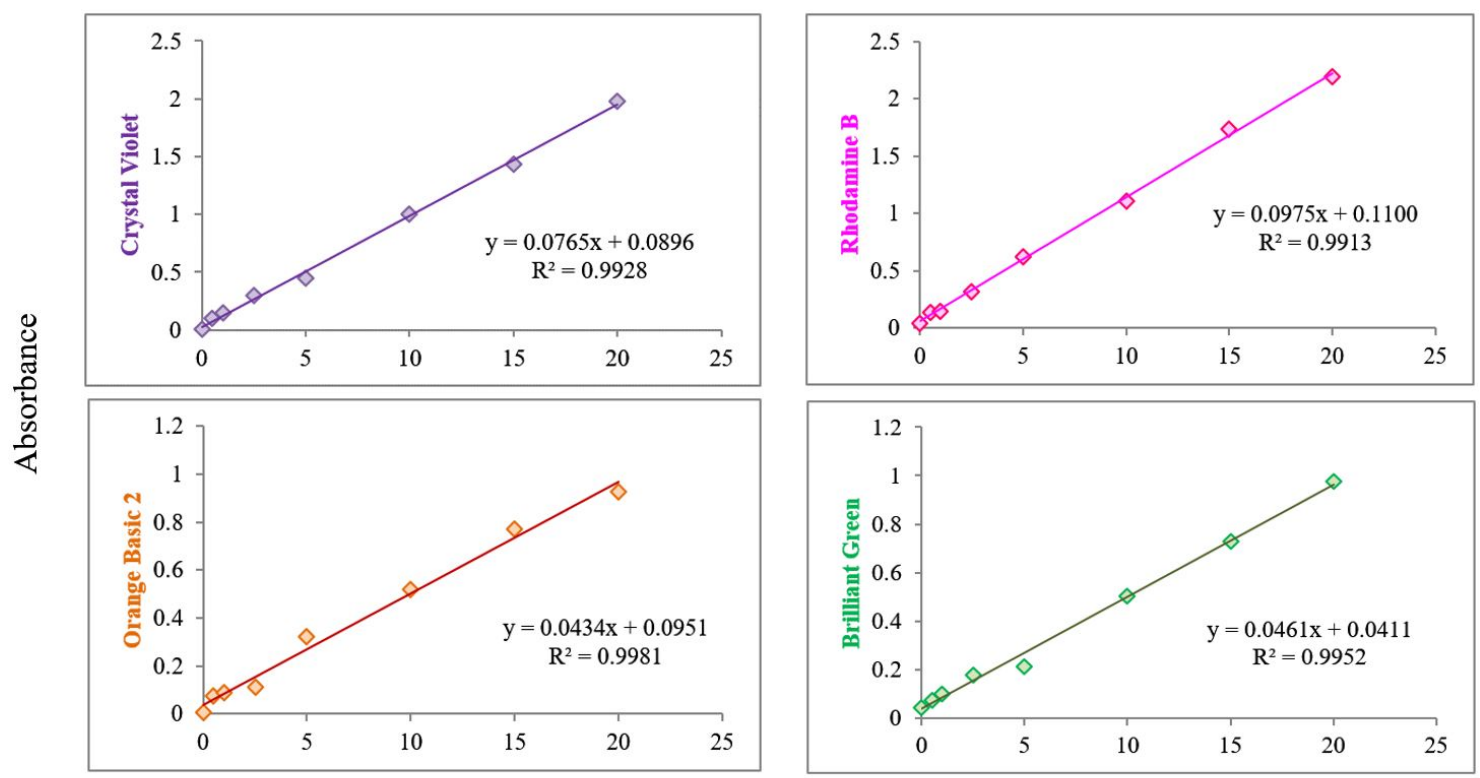

Concentration $\left(\mathrm{mg} \mathrm{L}^{-1}\right)$

Figure 5. Graphical representation of the concentration $\left(\mathrm{mg} \mathrm{L}^{-1}\right)$ versus absorbance. $(y=a x+b)$ linear correlation for the aqueous solutions of the dyes Crystal Violet, Brilliant Green, Orange Basic 2 and Rhodamine B: where $y=$ absorbance; $\mathrm{x}=$ dye concentration $\left(\mathrm{mg} \mathrm{L}^{-1}\right) ; \mathrm{R}^{2}=$ regression coefficient; $\mathrm{a}=$ angular coefficient; $\mathrm{b}=$ linear coefficient.

photocatalytic reactions and the optimum reaction temperature for photomineralization is said to be in the range of $20^{\circ} \mathrm{C}$ to $80^{\circ} \mathrm{C}$ [18] [19], therefore in this work the temperature of $30^{\circ} \mathrm{C}$ was established for all the experiments.

In a heterogeneous photocatalytic water system, $\mathrm{pH}$ is one of the most important operating parameters since the adsorption of the organic compound onto the photocatalyst surface degradation reaction depends on the surface charge of 
the photocatalyst and on the ionization state of the organic compound. Hence, the adsorption of positively charged organic compounds is facilitated at a basic $\mathrm{pH}$, while that of negatively charged species is favorable at an acidic $\mathrm{pH}$. Therefore, it is difficult to standardize the $\mathrm{pH}$ conditions for the degradation of a specific class of organic compounds. It is recommended that appropriate $\mathrm{pH}$ control strategies be implemented at every different condition of a photocatalytic water treatment process in order to get an efficient photocatalytic reaction [14] [20]. Figure 6 shows the effect of $\mathrm{pH}$ on decolorization of a $200 \mathrm{mg} \mathrm{L}^{-1}$ Rhodamine solution. The results confirm that the best efficiency was yielded at $\mathrm{pH} 10.0$ for an overall colour removal of this effluent. This is in accordance with the literature of the best decolorization performance of positively charged dyes (Rhodamine B, Basic Orange 2, Crystal violet, Brilliant Green) at basic pH [21] [22].

The concentration of the photocatalyst is another critical parameter that determines the degradation rate of any organic compound [23] as it relies upon the volume of the solution being treated and the initial concentration of the organic compound. It has been widely observed that the degradation rate increases with an increase in catalyst loading. This is due to the availability of more active catalyst sites at higher concentrations, which results in the generation of more hydroxyl species. However, when such load is increased beyond an optimum value, there is no appreciable increase in the degradation rate. This is due to fact that catalyst particles scatter light, reducing the effective light intensity reaching the bulk reaction solution. In the literature, $0.4-3.5 \mathrm{~g} \mathrm{~L}^{-1}$ of catalyst has been used for the photocatalytic degradation of different organic compounds [24]. Figure 7 shows the effect of catalyst concentration on decolorization of a $200 \mathrm{mg} \mathrm{L}^{-1}$ Rhodamine solution. The results confirmed a good performance with $1 \mathrm{~g} \mathrm{~L}^{-1}$, but the best efficiency was achieved with $2.5 \mathrm{~g} \mathrm{~L}^{-1}$ for both $\mathrm{TiO}_{2}$ and $\mathrm{ZnO}$. These results are close to those obtained by Sivalingam et al. [25] that observed that the

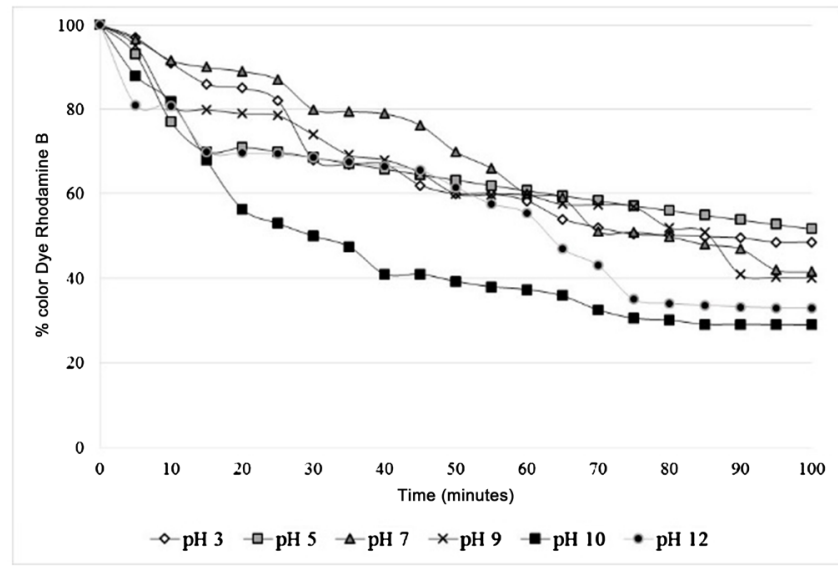

(a) $\mathrm{TiO}_{2}$

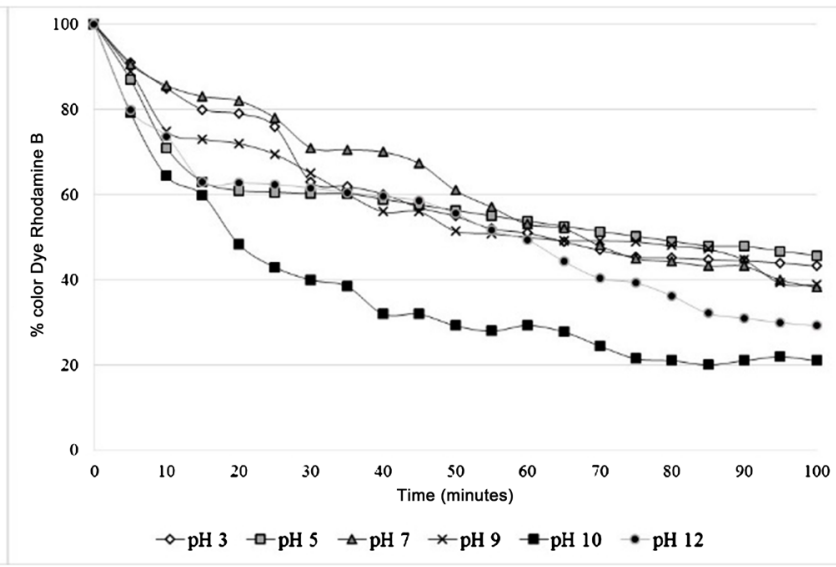

(b) $\mathrm{ZnO}$

Figure 6. Rhodamine $\mathrm{B}$ remaining as a function of UV irradiation time with $\mathrm{pH}$ ranging from 3 to 12 in a synthetic effluent com-

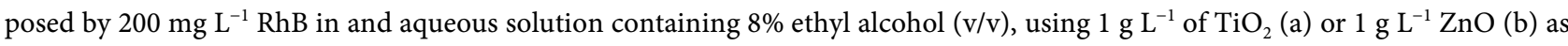
catalyst and temperature $30^{\circ} \mathrm{C}$ under constant stirring. 


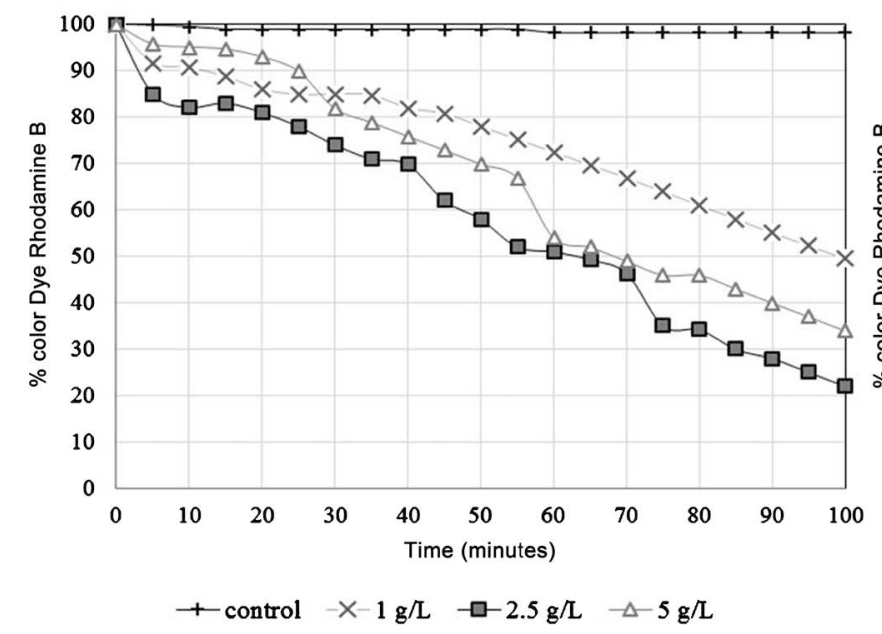

(a) $\mathrm{TiO}_{2}$

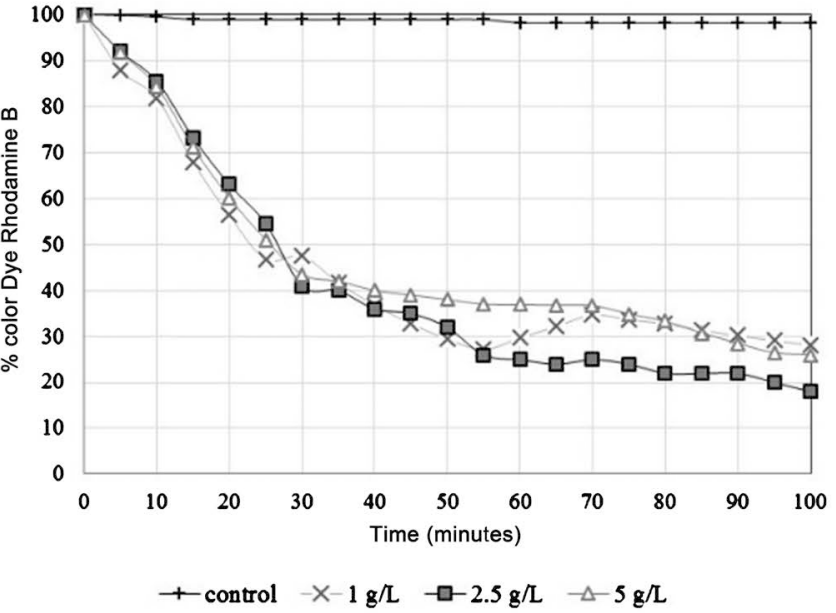

(b) $\mathrm{ZnO}$

Figure 7. Rhodamine B remaining as a function of $\mathrm{UV}$ irradiation time varying the concentration of catalyst from $1 \mathrm{~g} \mathrm{~L}^{-1}$ to $5 \mathrm{~g} \mathrm{~L}^{-1}$ in a synthetic effluent composed by $200 \mathrm{mg} \mathrm{L}^{-1} \mathrm{RhB}$ in and aqueous solution containing $8 \%$ ethyl alcohol (v/v), using $\mathrm{TiO}_{2}(\mathrm{a})$ and $\mathrm{ZnO}$ (b) as catalyst, at $\mathrm{pH} 10$ and $30^{\circ} \mathrm{C}$ temperature under constant stirring.

optimum added of $\mathrm{TiO}_{2}$ for the degradation of dyes is $1 \mathrm{~g} \mathrm{~L}^{-1}$. In the work of Ahmed et al. [15] the concentration of reactive yellow dye treated was $50 \mathrm{mg} \mathrm{L}^{-1}$ and the best $\mathrm{ZnO}$ catalyst dosage was found in $3.5 \mathrm{~g} \mathrm{~L}^{-1}$.

Degradation efficiency obtained for the aqueous/ethyl alcohol (8\%) solution containing the mixture of $200 \mathrm{mg} \mathrm{L}^{-1}$ of RhB, $200 \mathrm{mg} \mathrm{L}^{-1} \mathrm{CV}, 200 \mathrm{mg} \mathrm{L}^{-1} \mathrm{BR}$ and $200 \mathrm{mg} \mathrm{L}^{-1} \mathrm{BG}$ at $\mathrm{pH} 10.0$ with the presence of each catalyst $\left(\mathrm{TiO}_{2}\right.$ or $\left.\mathrm{ZnO}\right)$ as a function of time is presented in Figure 8. It is possible to observe that decolorization was successfully achieved. The color promoted by the dyes brilliant green and crystal violet was completely removed in a reaction time of 80 min under constant stirring. On the other hand, given the same amount of time, the discoloration reached on Rhodamine B or the composition made of Rhodamine B and Basic Orange 2 was only about $90 \%$. These results confirm Rhodamine B to be the most resistant to degradation dye among the colorants studied. Among the catalysts, $\mathrm{ZnO}$ presented a slightly better performance on all the studied dyes. Figure 9 shows the aspect of the dye solution before and after the dye degradation procedure carried out by heterogeneous photocatalysis.

Adsorption studies on the solid catalysts were performed and the results demonstrate that the adsorption of the dyes is not significant for these solutions under these conditions, presenting results of less than $0.03 \%$. For degradation control tests, considering the use of just the catalyst or just the UV irradiation, there was no discoloration above $0.006 \%$. Considering such findings, it is safe to assume that the process of decolorization is just associated to the formation of hydroxyl radicals $(\cdot \mathrm{OH})$ by the $\mathrm{UV} / \mathrm{TiO}_{2}$ or $\mathrm{UV} / \mathrm{ZnO}$ process. As expected, the $\mathrm{ZnO}$ catalyst produced better results than the $\mathrm{TiO}_{2}$, since, in comparison, it has a minor band gap energy and also is capable of providing a higher oxidation energy [20] [26] [27]. 

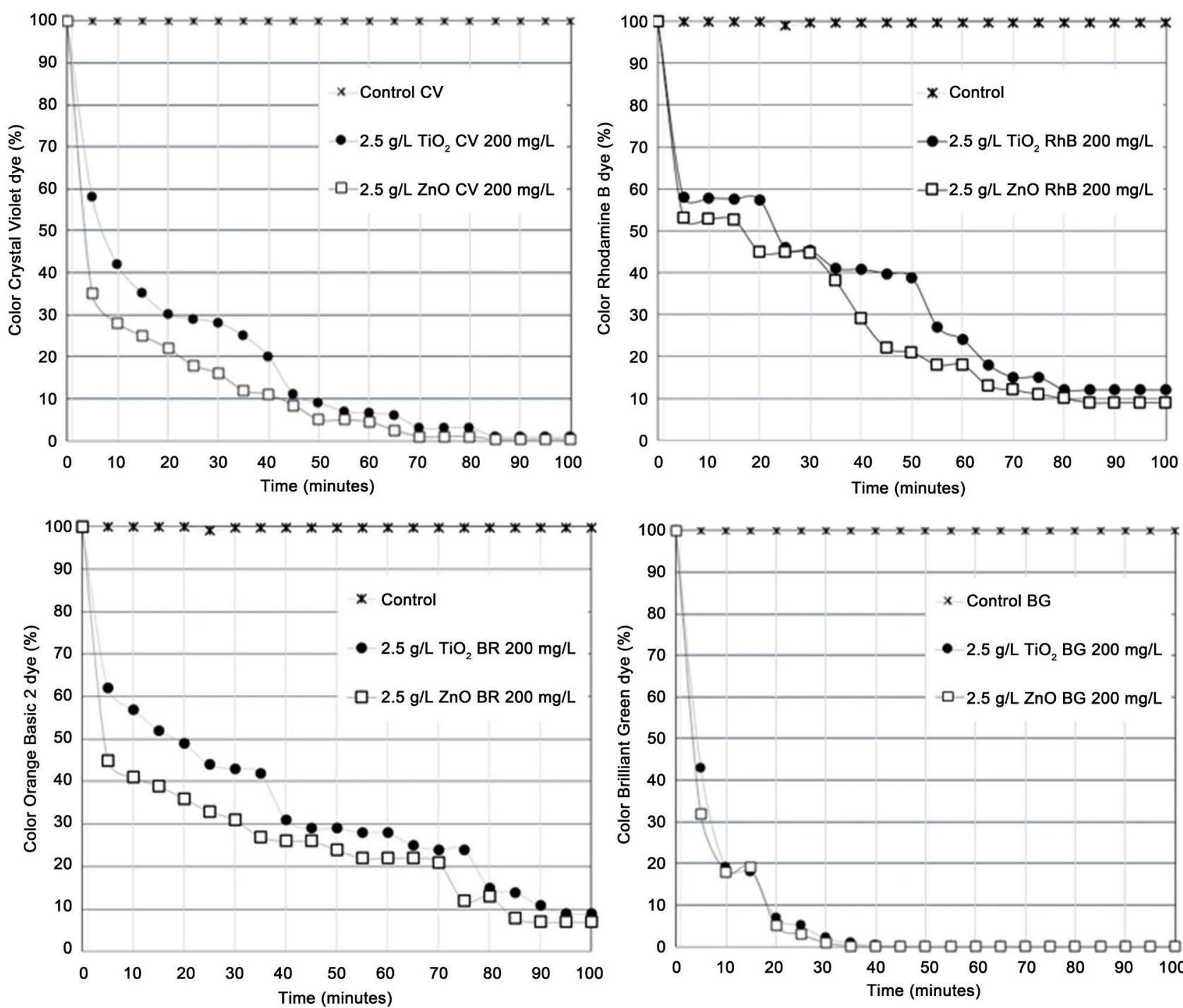

Figure 8. Colour remaining as a function of UV irradiation time for a synthetic solution containing $200 \mathrm{mg} \mathrm{L}^{-1}$ of each dye (RhB, $\mathrm{CV}, \mathrm{BR}, \mathrm{BG}$ ) in aqueous solution with $8 \%$ of ethyl alcohol (v/v). Treatment with $2.5 \mathrm{~g} \mathrm{~L}^{-1}$ of $\mathrm{TiO}_{2}$ and $\mathrm{ZnO}$, at $\mathrm{pH} 10$ and temperature of $30^{\circ} \mathrm{C}$ under constant stirring.
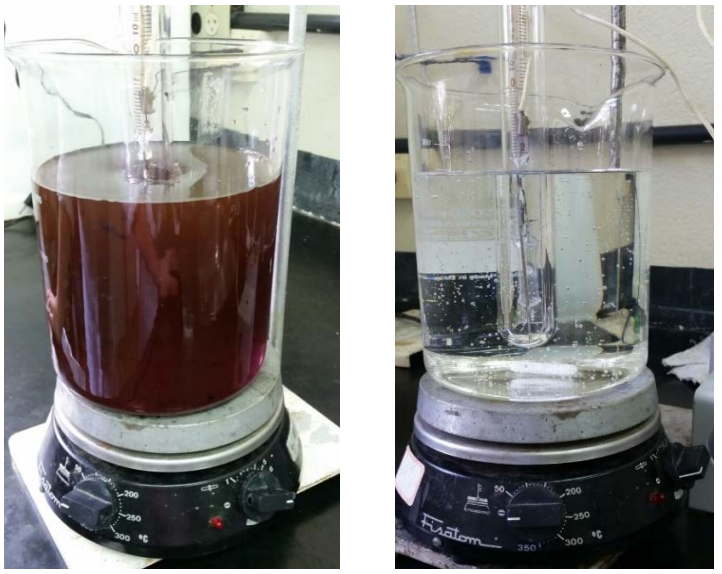

Figure 9. Aspect of the synthetic effluent containing the 4 dyes before and after the application of the photocatalytic treatment with $\mathrm{ZnO}\left(2.5 \mathrm{~g} \mathrm{~L}^{-1}\right.$ in aqueous solution with $8 \%$ ethyl alcohol), $\mathrm{UV}$ irradiation, temperature-controlled system at $30^{\circ} \mathrm{C}$ and $\mathrm{pH} 10$. 
Agate dyeing wastewaters always present highly recalcitrant dyes, in concentrations which can give water resources undesirable color when launched without treatment. The use of heterogeneous catalysis process is advantageous because it is built upon just energy and a catalyst without the need of any other chemical reagent and the catalyst can also be recovered after the end of each treatment process cycle and put back to use once again. The volumes of effluent produced, in the order of $0.2 \mathrm{~m}^{3}$ per $\mathrm{kg}$ of stained stones [8], are in the order of few $\mathrm{m}^{3}$ per week, which is totally suitable for oxidative processes like the heterogeneous photocatalysis. The process could be improved or associated to some other processes, such as ozonation or adsorption to improve the water quality parameters of discharge or even to allow water reuse in its own system.

\section{Conclusion}

The aqueous/ethyl alcohol solutions of Rhodamine B and the composition of Rhodamine B, Crystal Violet, Brilliant Green, and Blood Red were decolorized by heterogeneous photocatalysis in the system $\mathrm{UV} / \mathrm{TiO}_{2}$ and $\mathrm{UV} / \mathrm{ZnO}$. The best conditions found were 2.5 and $\mathrm{g} \mathrm{L}^{-1}$ of catalyst at $\mathrm{pH} 10$ and an irradiation time of $80 \mathrm{~min}$. The process resulted in the complete degradation of crystal violet, brilliant green and $80 \%$ - 90\% degradation of Rhodamine B and Blood Red. The proposed system can be adapted to small companies of agate processing in order to help with colour removal of dying wastewaters.

\section{Acknowledgements}

The authors would like to thank CAPES/Brazil for the scholarship grant, doctoral sandwich program abroad PDSE and Passo Fundo University for the Scientific Initiation scholarship Pibic/UPF.

\section{Conflicts of Interest}

The authors declare no conflicts of interest regarding the publication of this paper.

\section{References}

[1] Hartmann, L.A. and Silva, J.T.D. (2010) Tecnologias para o setor de gemas, joias e mineração. 1. Centro Tecnologia de Pedras, Gemas e Joias do rio Grande do Sul.

[2] Knecht, T. (1957) Coloração artificial de ágatas. Revista da Associação Brasileira de Gemologia, 7, 1-9.

[3] Bosi, L. (1999) Industrial Treatment of Raw Agate: Cutting, Chemical Thermal Treatment, Polishing for Obtation of Coloured Agate Plate. ENPROMER'99. In: II Congresso de Engenharia de Processos do MERCOSUL, Florianópolis, Santa Catarina, Brasil of Conference.

[4] Silva, R.D.A., Petter, C.O. and Schneider, I.A.H. (2007) Avaliação da perda da coloração artificial de ágatas. Rem: Revista da Escola de Minas, 60, 477-482. http://www.lume.ufrgs.br/handle/10183/21034

[5] Yazdi, M., Lotfi, R., Masoudi, F. And Pak, N.M. (2016) Chemical Treatment Effects 
of Blue, Yellow and Green Colors with Heating Methods on Agates of Cheshme Shoor Area, Qom, Iran. Journal of Minerals and Materials Characterization and Engineering, 4, 210-217. https://doi.org/10.4236/jmmce.2016.43019

[6] IBGM. (2018) Brazilian Institute of Gems and Precious Minerals-The Sector in Numbers. http://ibgm.com.br/ibgm-informa/publicacoes/

[7] DNPM, Anuário Mineral Estadual Rio Grande do Sul, Brasil, in Departamento Nacional De Produção Mineral-Superintendência Do Rio Grande Do Sul. 2018, Ministério De Minas E Energia-MME, Superintendência Do Rio Grande Do Sul: Brasília, DF, p. 57.

[8] Vilasbôas, F.D.S., Santos, C.R.D. and Schneider, I.A.H. (2017) Environmental Issues on the Industrial Processing of Raw Agate. Geomaterials, 7, 13-24.

https://doi.org/10.4236/gm.2017.71002

[9] CONSEMA/RS (2017) Resolution 355/2017: Provides Criteria and Standards for the Emission of Liquid Effluents to the Generating Sources that Discharge Their Effluents into Surface Waters in the State of Rio Grande do Sul, 7.

http://www.sema.rs.gov.br/upload/arquivos/201707/19110149-355-2017-criterios-epadroes-de-emissao-de-efluentes-liquidos.pdf

[10] Pizzolato, T.M., Carissimi, E., Machado, E.L. and Schneider, I.A.H. (2002) Colour Removal with $\mathrm{NaClO}$ of Dye Wastewater from an Agate-Processing Plant in Rio Grande do Sul, Brazil. International Journal of Mineral Processing, 65, 203-211. https://doi.org/10.1016/S0301-7516(01)00082-5

[11] Machado, Ê.L., De Sales Dambros, V., Kist, L.T., Alcayaga Lobo, E.A., Tedesco, S.B. and Moro, C.C. (2012) Use of Ozonization for the Treatment of Dye Wastewaters Containing Rhodamine B in the Agate Industry. Water, Air, \& Soil Pollution, 223, 1753-1764. https://doi.org/10.1007/s11270-011-0980-9

[12] Barros, A.L., Pizzolato, T.M., Carissimi, E. and Schneider, I.H. (2006) Decolorizing Dye Wastewater from the Agate Industry with Fenton Oxidation Process. Minerals Engineering, 19, 87-90. https://doi.org/10.1016/j.mineng.2005.04.004

[13] Herrmann, J.-M. (1999) Heterogeneous Photocatalysis: Fundamentals and Applications to the Removal of Various Types of Aqueous Pollutants. Catalysis Today, 53, 115-129. https://doi.org/10.1016/S0920-5861(99)00107-8

[14] Muhd Julkapli, N., Bagheri, S. and Bee Abd Hamid, S. (2014) Recent Advances in Heterogeneous Photocatalytic Decolorization of Synthetic Dyes. The Scientific World Journal, 2014, 25. https://doi.org/10.1155/2014/692307

[15] Ahmed, L.M., Tawfeeq, F.T., Al-Ameer, M.H.A., Al-Hussein, K.A. and Athaab, A.R. (2016) Photo-Degradation of Reactive Yellow 14 Dye (A Textile Dye) Employing $\mathrm{ZnO}$ as Photocatalyst. Journal of Geoscience and Environment Protection, 4, 11. https://doi.org/10.4236/gep.2016.411004

[16] Campos, M.L.M., Mello, L.C., Zanette, D.R., Sierra, M.M.D.S. and Bendo, A. (2001) Construção e otimização de um reator de baixo custo para a fotodegradação da matéria orgânica em águas naturais e sua aplicação no estudo da especiação do cobre por voltametria. Química Nova, 24, 257-261. https://doi.org/10.1590/S0100-40422001000200018

[17] Chong, M.N., Jin, B., Chow, C.W.K. and Saint, C. (2010) Recent Developments in Photocatalytic Water Treatment Technology: A Review. Water Research, 44, 2997-3027. https://doi.org/10.1016/j.watres.2010.02.039

[18] Malato, S., Fernández-Ibáñez, P., Maldonado, M.I., Blanco, J. and Gernjak, W. (2009) Decontamination and Disinfection of Water by Solar Photocatalysis: Recent overview and Trends. Catalysis Today, 147, 1-59. 
https://doi.org/10.1016/j.cattod.2009.06.018

[19] Devi, G.L., Narasimha Murthy, B. and Girish Kumar, S. (2009) Heterogeneous Photo Catalytic Degradation of Anionic and Cationic Dyes over $\mathrm{TiO} 2$ and $\mathrm{TiO} 2$ Doped with Mo6+ Ions under Solar Light: Correlation of Dye Structure and Its Adsorptive Tendency on the Degradation Rate. Chemosphere, 76, 1163-1166. https://doi.org/10.1016/j.chemosphere.2009.04.005

[20] Rajeshwar, K., Osugi, M.E., Chanmanee, W., Chenthamarakshan, C.R., Zanoni, M.V.B., Kajitvichyanukul, P. and Krishnan-Ayer, R. (2008) Heterogeneous Photocatalytic Treatment of Organic Dyes in Air and Aqueous Media. Journal of Photochemistry and Photobiology C: Photochemistry Reviews, 9, 171-192. https://doi.org/10.1016/j.jphotochemrev.2008.09.001

[21] Lee, K.M., Lai, C.W., Ngai, K.S. and Juan, J.C. (2016) Recent Developments of Zinc Oxide Based Photocatalyst in Water Treatment Technology: A Review. Water Research, 88, 428-448. https://doi.org/10.1016/j.watres.2015.09.045

[22] Zangeneh, H., Zinatizadeh, A.L., Habibi, M., Akia, M. and Hasnain Isa, M. (2015) Photocatalytic Oxidation of Organic Dyes and Pollutants in Wastewater Using Different Modified Titanium Dioxides: A Comparative Review. Journal of Industrial and Engineering Chemistry, 26, 1-36.

https://doi.org/10.1016/j.jiec.2014.10.043

[23] Wang, Y., Mo, Z., Zhang, P., Zhang, C., Han, L., Guo, R., Gou, H., Wei, X. and Hu, R. (2016) Synthesis of Flower-Like $\mathrm{TiO}_{2}$ Microsphere/Graphene Composite for Removal of Organic Dye from Water. Materials \& Design, 99, 378-388. https://doi.org/10.1016/j.matdes.2016.03.066

[24] Syed Nabeel, A. and Waseem, H. (2018) Heterogeneous Photocatalysis and Its Potential Applications in Water and Wastewater Treatment: A Review. Nanotechnology, 29, Article ID: 342001. https://doi.org/10.1088/1361-6528/aac6ea

[25] Sivalingam, G., Priya, M.H. and Madras, G. (2004) Kinetics of the Photodegradation of Substituted Phenols by Solution Combustion Synthesized $\mathrm{TiO}_{2}$. Applied Catalysis B: Environmental, 51, 67-76. https://doi.org/10.1016/j.apcatb.2004.02.006

[26] Siuleiman, S., Kaneva, N., Bojinova, A., Papazova, K., Apostolov, A. and Dimitrov, D. (2014) Photodegradation of Orange II by $\mathrm{ZnO}$ and $\mathrm{TiO}_{2}$ Powders and Nanowire $\mathrm{ZnO}$ and $\mathrm{ZnO} / \mathrm{TiO} 2$ Thin Films. Colloids and Surfaces A: Physicochemical and Engineering Aspects, 460, 408-413. https://doi.org/10.1016/j.colsurfa.2014.01.010

[27] Schrauben, J.N., Hayoun, R., Valdez, C.N., Braten, M., Fridley, L. and Mayer, J.M. (2012) Titanium and Zinc Oxide Nanoparticles Are Proton-Coupled Electron Transfer Agents. Science, 336, 1298. https://doi.org/10.1126/science.1220234 